\title{
Development of a Portable Rainfall Simulation System for Hydrologic Studies under Field Conditions
}

\author{
Sachin Kumar Singh* and Akhilesh Kumar
}

Department of Soil and Water Conservation Engineering, College of Technology, G. B. Pant University of Agriculture and Technology, Pantnagar-263145, Uttarakhand, India.

*Corresponding author

\begin{tabular}{l} 
K e y w o r d s \\
Rainfall simulation, \\
Portable rainfall \\
simulator, \\
Hydrologic studies, \\
Field conditions \\
\hline Article Info \\
Accepted: \\
15 December 2019 \\
Available Online: \\
20 January 2020
\end{tabular}

Keywords

Rainfall simulation, Portable rainfall simulator

Hydrologic studies, Article Info

Accepted:

15 December 2019

20 January 2020

\section{A B S T R A C T}

In hydrologic studies rainfall and soil system are two important considerations. It is always desirable to conduct these studies under field conditions in order to represent actual conditions. Rainfall simulation offers a viable alternative to conduct hydrologic studies under controlled conditions. Various types of rainfall simulators are already available for this purpose, but most of them are fixed type and can be used in a laboratory. In such studies a tilting flume filled with soil is used as the test plot. In this study, a portable rainfall has been developed and tested in order to conduct hydrologic studies under actual field conditions. This light weight simulation system and its various components are mounted on wheels to take them to field easily. The portable rainfall simulator is capable of producing rainfall similar to natural rainfall with its intensity in the range of $3.77 \mathrm{~cm} / \mathrm{h}$ to $12.73 \mathrm{~cm} / \mathrm{h}$, uniformity coefficient ranging from $82.81 \%$ to $93.52 \%$, drop size in the range of $2.96 \mathrm{~mm}$ to $4.81 \mathrm{~mm}$ with terminal velocity of rain drops ranging from $8.39 \mathrm{~m} / \mathrm{s}$ to $10.69 \mathrm{~m} / \mathrm{s}$.

\section{Introduction}

To conduct hydrologic studied related to rainfall-runoff-sediment outflow, apart from rainfall parameters, soil conditions, cropping systems and nature of management practices are invariably considered. Ideally, these studies should be conducted under actual field conditions with natural rainfall. However, temporal and spatial uncertainty in the occurrence of natural rainfall events becomes a very serious handicap to conduct these studies under actual field conditions. Owing to uncertain and beyond human control, to conduct and replicate field study not only becomes a tedious, time consuming and labour 
intensive task. Further, lack of validation of results under similar conditions may lead to approximations and erroneous outcomes. To overcome these practical difficulties, rainfall simulation has been considered as a alternative to conduct hydrologic studies under controlled conditions. Various types of rainfall simulators are already available for this purpose. These rainfall simulators are, generally, installed at a particular place to facilitate hydrological studies under controlled conditions of a laboratory (Meyer, 1965, 1988, Lascelles et al., 2000, Dunkeley, 2008 Corona et al., 2013, and Singh and Kashyap 2016).

With rainfall generation, is within human control in the form of simulated rainfall, the next constraint in such studies remained to create natural soil conditions. Normally, a tilting flume or a test tray filled with soil is used as the test plot. In case of created test plots, it has been observed that soil parameters do change according to compaction applied during filling of soil in the test plot it does not exactly represent natural soil conditions. Also, in these test plots consideration of different types of soil is a problem, as filling and refilling of different types of soil every time becomes labour consuming herculean task.

In order to overcome these practical difficulties and to also to enhance the quality of hydrological research, it was conceived to design and develop a portable rainfall simulation system which is light in weight, easy to assemble and disassemble and capable of generating artificial rainfall similar to natural rainfall with varying intensities. This portable rainfall simulation system can be taken to the experiment site to conduct experiments under natural conditions of a field.

In general, rainfall simulators have been developed using nozzles. These nozzle type rainfall simulators work under high pressure and fail to produce raindrops of desired size with desired terminal velocities similar to natural rainfall. The lower terminal velocity in combination with the smaller drop-size results in lower kinetic energy than that produced by natural rainfall. In general, the Kinetic energy of simulators with nozzle-type drop formers and free-falling drops is frequently $40-50 \%$ of natural rain Junior and Siqueira (2011) apart from being bulky and stationary.

In view of the above, the development of portable rainfall simulation system which is capable of producing rainfall having its parameters similar to natural rainfall can be used for runoff and soil erosion studies in situ will prove to be very effective tool to conduct hydrologic studies. This will lead to enhancement of the quality of hydrologic studies as it will overcome various constraints being faced presently. Accordingly, in this study an attempt has been made to develop a rainfall simulation system which portable and capable of generating artificial rainfall similar to the natural rainfall. The portable rainfall simulation is $3.4 \mathrm{~m}$ long and $1.4 \mathrm{~m}$ wide has been developed by using hypodermic needles fixed at a specified spacing. The rainfall generation unit is placed at $6.0 \mathrm{~m}$ height from the ground on a frame made of mild steel pipes. The entire rainfall simulation system consists of three units as the base, supporting structure, rainfall generation and water supply units. The entire assembly can be dissembled and assembled easily and is mounted on wheels to facilitate easy movement to one place to another.

\section{Materials and Methods}

\section{Design and fabrication}

This portable rainfall simulation system (Fig. 1) consists of four units as rainfall generation and control unit, supporting structure for rainfall generation unit, water supply and 
control unit, movable base unit and has been designed accordingly. The details of design and construction of these units are described below.

\section{Rainfall generation and control unit}

The rainfall generation unit $3.2 \mathrm{~m} \times 1.2 \mathrm{~m}$ in size (Fig. 2) was fabricated by using lightweight aluminium pipes and PVC pipes which is mainly responsible for the generation of rainfall. The hypodermic needles of 20 gauge size and $5 \mathrm{~cm}$ long with square base were mounted in upward direction on $1 \mathrm{x} 1 \mathrm{~cm}$ square pipes with the help of a strong adhesive. These hypodermic needles were placed keeping a square grid of $20 \times 20 \mathrm{~cm}$ as per the earlier work Kumar et al. (2004). The aluminium square pipe lateral was connected to peripheral water supply line made up of $2.54 \mathrm{~cm}$ dia PVC pipes. Care was taken to make all the connections water tight to avoid leakage and pressure drop.

The control of rainfall parameters was done by regulating water pressure using a regulatory valve mounted on the water supply line. The water pressure was recorded with the help of a pressure gauge provided just before the peripheral supply line which receives pressurized water from a mono block centrifugal pump. The simulation system was provided protection from the wind effects with the help of a wind guard mounted all around the simulation system on its outer periphery with the help of rope from the top of the supporting structure.

\section{Supporting frame for rainfall generation unit}

The rainfall generation unit was supported on a $3.40 \mathrm{~m} \times 1.40 \mathrm{~m}$ rectangular frame made of mild steel light weight square pipes. The supporting frame consists of two vertical stands mounted on square base frame. The supporting frame was fitted at a height of $6 \mathrm{~m}$ with the help of mild steel pipes which provided strength to the rainfall generation unit.

The rainfall generation unit was placed at a height so that the falling rain drops attain a terminal velocity in the range of $8.39 \mathrm{~m} / \mathrm{s}$ to $10.69 \mathrm{~m} / \mathrm{s}$ similar to natural rain. The rainfall simulation unit could be moved up and down with the help of rope and pulley arrangement made at the top of the supporting structure.

\section{Water supply and control unit}

The water supply unit consists of a water storage tank of 500 litre capacity and a $1 \mathrm{hp}$ mono block centrifugal pump, which supply pressurised water to rainfall generation unit through a flexible supply line. The water storage tank with centrifugal pump and accessories are mounted over a $1.5 \mathrm{~m} \times 1 \mathrm{~m}$ movable platform. The water pressure is regulated by flow regulation valve and a bypass system which is monitored using a pressure gauge of $0-2 \mathrm{~kg} / \mathrm{cm}^{2}$ range. This pressure gauge mounted on the water supply line indicates the pressure at which water is supplied to the simulation unit.

\section{Movable base unit}

The movable base unit facilitates the entire rainfall system to move from one location to another is a metallic rectangular frame of 3.4 $\mathrm{m} \times 1.4 \mathrm{~m}$ size. The flange joints were used to assemble the unit which provided strength to whole base structure. The base structure is mounted on four PVC caster wheels of 250 $\mathrm{mm}$ size made by polyvinyl chloride. These wheels are light weight, durable and strong enough to bear the load. Two of the wheels were provided with break mechanism, which helps to control the movement of the unit and also work as locking device when simulator is in operation. 


\section{Calibration of simulation system}

Once the simulation system is ready, it was tested for its performance by determining simulated rainfall parameters at varying water pressure. To obtain simulated rainfall parameters in the range of natural rainfall, the simulator was operated and calibrated at different water pressures for parameters like rainfall intensity, drop size, uniformity of distribution. The use of hypodermic needles and placement of the rainfall generation unit at $6 \mathrm{~m}$ height ensures almost vertical impact angle of falling raindrops with a terminal velocity in the range of $8.39 \mathrm{~m} / \mathrm{s}$ to $10.69 \mathrm{~m} / \mathrm{s}$ similar to natural rainfall. The water pressure range in which satisfactory values of simulated rainfall intensity, drop size, terminal velocity and rainfall distribution are obtained was selected. The determination of these parameters was done as per the following procedure.

\section{Rainfall intensity}

The rainfall intensity is the most important parameter in the rainfall simulation studies. In the present study, an average value of simulated rainfall intensity $\left(I_{a}\right) \mathrm{cm} / \mathrm{h}$ was determined at any selected operating pressure with the help of the following relationship:

$\mathrm{I}_{\mathrm{a}}=\left[\sum\left\{\left(\frac{V_{i}}{A_{i}}\right)\right\} /(N x t)\right] \times 60$

Where $V_{i}$ is the volume of water collected, cc; $A_{i}$ is the cross section area of the $\mathrm{i}^{\text {th }}$ catch can, $\mathrm{cm}^{2} ; \mathrm{N}$ is the total number of catch cans used and $\mathrm{t}$ is the collection time, min.

\section{Uniformity coefficient}

Uniformity coefficient (UC) provides the basis for quantitative assessment of the uniformity in the distribution of falling rainfall on an area. The uniformity coefficient of the simulated rain was calculated with the help of following relationship as proposed by Christiansen (1942).

$U_{c}=\left[1-\sum \frac{X_{i}}{M N}\right] \times 100$

where $\mathrm{U}_{\mathrm{c}}$ is the uniformity coefficient, \%; $\mathrm{X}_{\mathrm{i}}$ is the deviation of depth of water collected in $\mathrm{i}^{\text {th }}$ catch can from the mean depth, $\mathrm{mm}$; $\mathrm{M}$ is the mean value of depth of water collected in all the catch cans, $\mathrm{mm}$. In the present case, all the catch cans were of the same crosssectional area, so, Eq. 2 may be expressed as,

$$
U_{c}=\left[1-\dot{a} V_{i} /(V N)\right] \times 100
$$

where $\mathrm{V}_{i}$ is the deviation of volume collected in $\mathrm{i}^{\text {th }}$ catch can from the mean volume, cc.

\section{Rain drop size}

The drop size of simulated rain was measured using the flour tray method as described by Bentley 1904, Carter et al. 1974 and Kathiravelu et al. 2016. In this method a $2 \mathrm{~cm}$ thick compacted layer of wheat flour was created in a container. The flour container was passed horizontally and swiftly through the rainfall. The flour was then dried for $24 \mathrm{~h}$ at ambient temperature $\left(28-30^{\circ} \mathrm{C}\right)$ and dry pellets of same size were collected to measure their size with the help of simple microscope. Several observations were taken at each water pressure to arrive at a decision. The procedure was repeated for every selected water pressure within the operating range.

\section{Terminal velocity}

The terminal velocity is the velocity of falling rain drops when raindrop while falling in the air, the frictional resistance of the air becomes equal to the gravitational acceleration. At this stage, raindrops continue to fall at a constant velocity called as terminal velocity. In the case of developed rainfall simulator hypodermic needles were used and the rainfall producing 
unit was mounted at a height of $5.0 \mathrm{~m}$ above the test plot. The water jet from the needles rise up to a height of $1 \mathrm{~m}-1.5 \mathrm{~m}$, depending upon operating pressure, breaks into droplets which fall downward from a total height of 6.0 $\mathrm{m}$ to $6.5 \mathrm{~m}$ under the effect of gravity. The terminal velocity of spherical raindrop was calculated for different raindrop sizes at different operating pressures were obtained with the help of following relationship (Chow \& Harbaugh 1965).

$V_{t}=\left[4 g \frac{D_{s}\left(\rho_{w}-\rho_{a}\right)}{3 c_{d} \times \rho_{a}}\right]^{0.5}$

where, $V_{t}$ is the terminal velocity of rain drops, $\mathrm{m} / \mathrm{s} ; \mathrm{D}_{\mathrm{s}}$ is drop size, $\mathrm{mm} ; \rho_{\mathrm{w}}$ and $\rho_{\mathrm{a}}$ are mass densities of water and air, $\mathrm{g} / \mathrm{cm}^{3} ; \mathrm{g}$ is gravitational acceleration $\mathrm{m} / \mathrm{s}^{2}$ and $\mathrm{C}_{\mathrm{d}}$ is the drag coefficient.

\section{Results and Discussion}

It was observed that the developed portable rainfall simulation system produced rainfall intensities in the range of $3.77 \mathrm{~mm} / \mathrm{h}$ to 12.73 $\mathrm{cm} / \mathrm{h}$ in the operating pressure increased from $0.12 \mathrm{~kg} / \mathrm{cm}^{2}$ to $0.80 \mathrm{~kg} / \mathrm{cm}^{2}$. The uniformity coefficient was found to be varying in the range from $82.81 \%$ to $91.49 \%$ in the same pressure range of $0.12 \mathrm{~kg} / \mathrm{cm}^{2}$ to $0.80 \mathrm{~kg} / \mathrm{cm}^{2}$. Both these parameters were found to be increasing with the increase in operating pressure. The raindrop was found to be decreasing with the increase in operation pressure and was recorded as $4.81 \mathrm{~mm}$ for the pressure of $0.12 \mathrm{~kg} / \mathrm{cm}^{2}$ and $2.96 \mathrm{~mm}$ for 0.80 $\mathrm{kg} / \mathrm{cm}^{2}$. These recorded parameters of simulated rainfall as obtained as obtained by using developed portable rainfall simulator for different water pressures are presented in Table 1.

The variation in simulated rainfall parameters with operating pressure is shown in Fig 2. to Fig. 6. It is evident that simulated rainfall intensity has almost a linear increasing trend while raindrop size has a decreasing trend with increase in operating pressure. In this study, depending on the average rainfall intensity range of Tarai region at Pantnagar, the range of simulated rainfall intensity from $3.77 \mathrm{~cm} / \mathrm{h}$ to $12.73 \mathrm{~cm} / \mathrm{h}$ was selected which was obtained in an operating pressure range of of 0.12 to $0.80 \mathrm{~kg} / \mathrm{cm}^{2}$. The drop size produced by the developed rainfall simulator in the range of $2.96 \mathrm{~mm}$ to $4.81 \mathrm{~mm}$ was also within the drop size range of 2 to $6 \mathrm{~mm}$ as is the case of natural rainfall (Gunn and Kinzer). The uniformity coefficient was found to be varying randomly in the range of $82.81 \%$ to $94.49 \%$ and did not have any trend with operating pressure.

According to (Bubenzer 1979) a value of uniformity coefficient more than $80 \%$ may considered quite satisfactory in rainfall simulation studies. The simulated rainfall has the terminal fall velocity in the range of similar to natural rainfall as jet of hypodermic needles rise for a height of about $1 \mathrm{~m}-1.5 \mathrm{~m}$, depending upon operating pressure, breaks into droplets which fall downward under the effect of gravity. Also, in this case, rain drops fall almost vertically resembling natural rainfall instead of falling downward conically at a certain angle as in case of nozzle type rainfall simulators.

Following mathematical relationships were developed to correlate parameters of simulated rainfall

$$
\begin{gathered}
\mathrm{I}_{\mathrm{a}}=13.588 \mathrm{p}+2.753 \\
\mathrm{r}^{2}=97.19 \% \\
\mathrm{D}_{\mathrm{s}}=-2.897 \mathrm{p}+5.494 \\
\mathrm{r}^{2}=85.7 \% \\
\mathrm{~V}_{\mathrm{t}}=1.2345 \mathrm{Ds}+4.7692 \\
\mathrm{r}^{2}=99.91 \%
\end{gathered}
$$

where, $I_{a}$ is the intensity of simulated rainfall, $\mathrm{cm} / \mathrm{h} ; \mathrm{D}_{\mathrm{s}}$ is the raindrop size, $\mathrm{mm}, \mathrm{p}$ is the operating pressure, $\mathrm{kg} / \mathrm{cm}^{2}$ and $\mathrm{V}_{\mathrm{t}}$ is the terminal velocity of rain drops. 


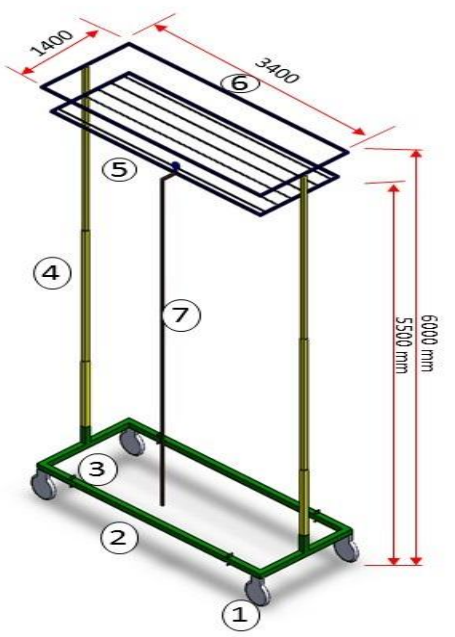

\section{Hypodermic needles}

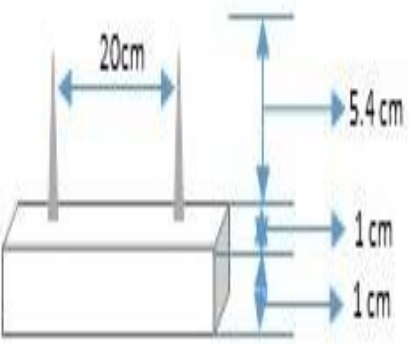

1. Pvc caster wheel

2. Base Frame

3. Flange joints

4. Supporting structure

5. Rainfall generation unit

6. Upper supporting structure

7. Water supply line

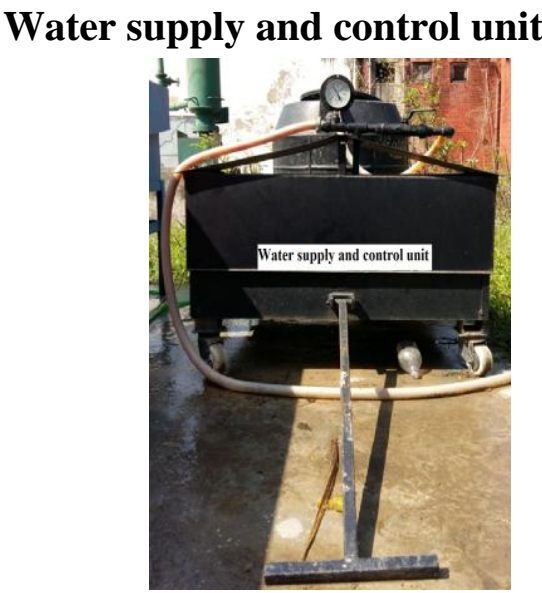

Fig.1 Portable rainfall simulation system

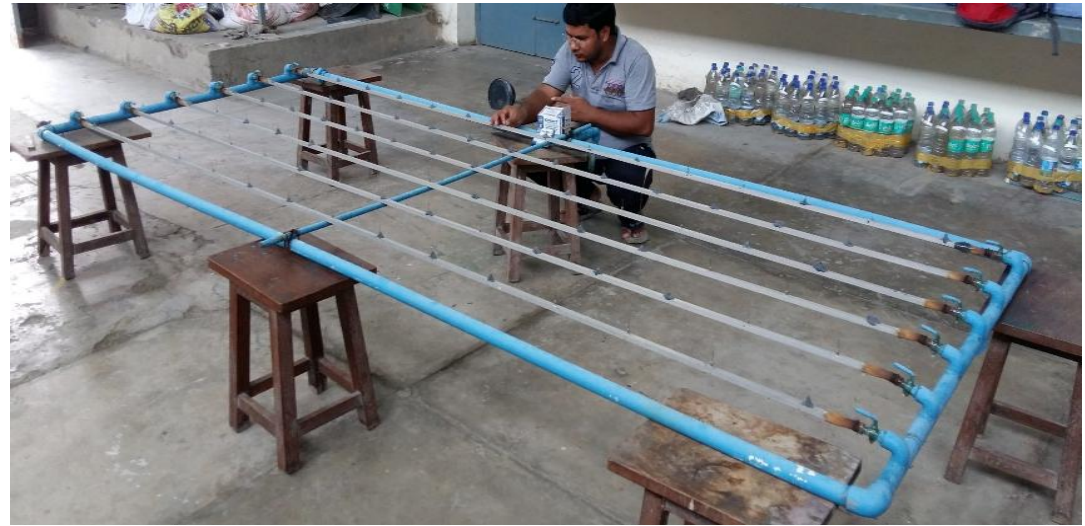

Fig.2 Rainfall generation unit 
Table.1 Recorded values of simulated rainfall parameters obtained by using developed portable rainfall simulator for different operating pressures

\begin{tabular}{|c|c|c|c|c|c|}
\hline SI. No. & $\begin{array}{c}\text { Operating } \\
\text { pressure, } \\
\mathbf{k g} / \mathbf{c m}^{\mathbf{2}}\end{array}$ & $\begin{array}{c}\text { Intensity of } \\
\text { rainfall, } \\
\mathbf{c m} / \mathbf{h}\end{array}$ & $\begin{array}{c}\text { Uniformity } \\
\text { coefficient, } \\
\mathbf{\%}\end{array}$ & $\begin{array}{c}\text { Raindrop size, } \\
\mathbf{m m}\end{array}$ & $\begin{array}{c}\text { Terminal } \\
\text { velocity, } \\
\mathbf{m} / \mathbf{s}\end{array}$ \\
\hline $\mathbf{1}$ & 0.12 & 3.77 & 82.81 & 4.81 & 10.69 \\
\hline $\mathbf{2}$ & 0.22 & 6.09 & 91.74 & 4.68 & 10.54 \\
\hline $\mathbf{3}$ & 0.32 & 6.95 & 87.49 & 4.92 & 10.81 \\
\hline $\mathbf{4}$ & 0.42 & 8.82 & 87.53 & 4.45 & 10.28 \\
\hline $\mathbf{5}$ & 0.52 & 9.73 & 91.81 & 4.41 & 10.24 \\
\hline $\mathbf{6}$ & 0.60 & 11.63 & 88.35 & 3.77 & 9.46 \\
\hline $\mathbf{7}$ & 0.70 & 12.58 & 93.52 & 3.24 & 8.77 \\
\hline $\mathbf{8}$ & 0.80 & 12.73 & 91.49 & 2.96 & 8.39 \\
\hline
\end{tabular}

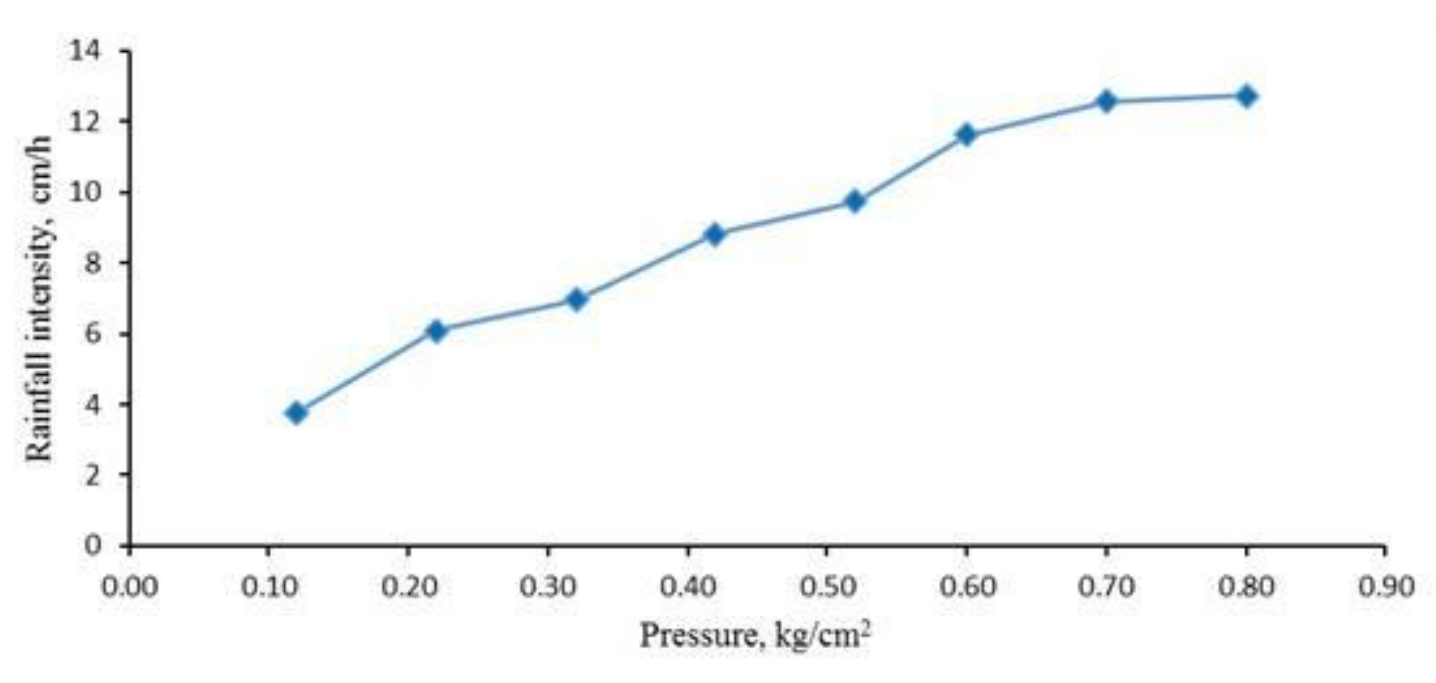

Fig.3 Variation in simulated rainfall intensity with operating pressure 


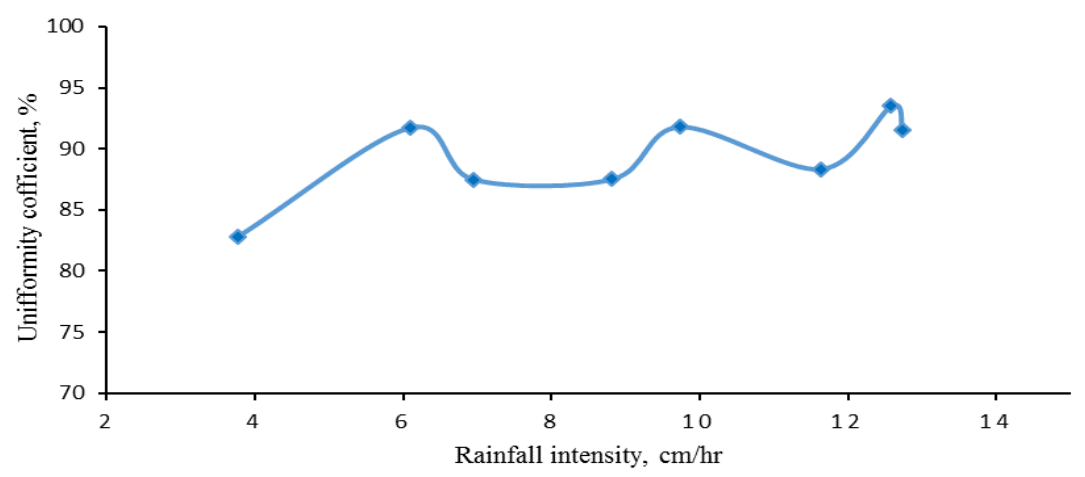

Fig. 4 Variation in uniformity coefficient with simulated rainfall intensity

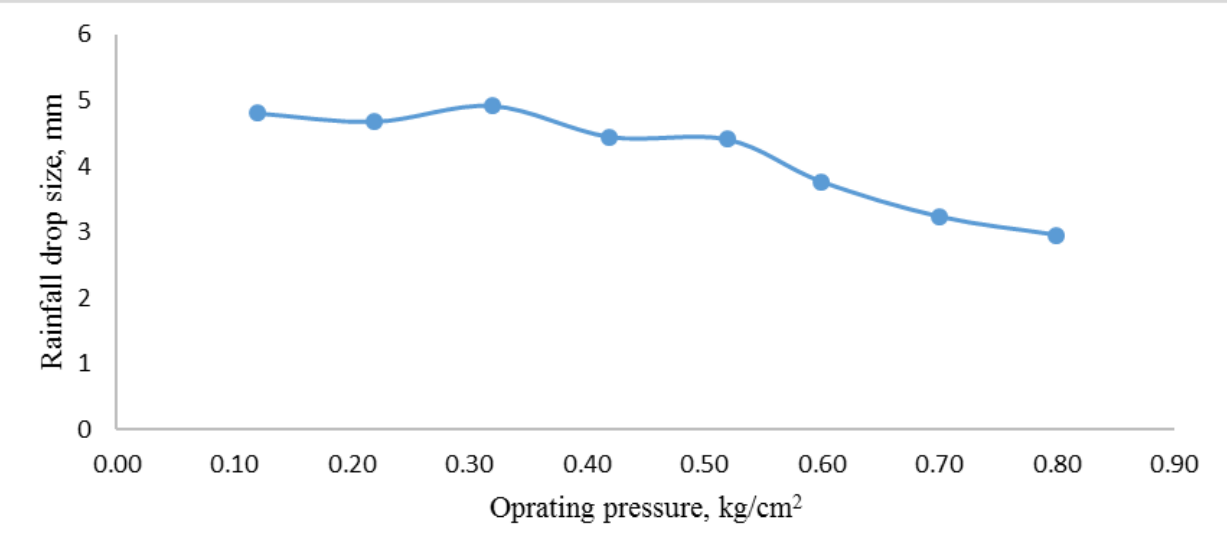

Fig.5 Variation in raindrop size of simulated rainfall with operating pressure

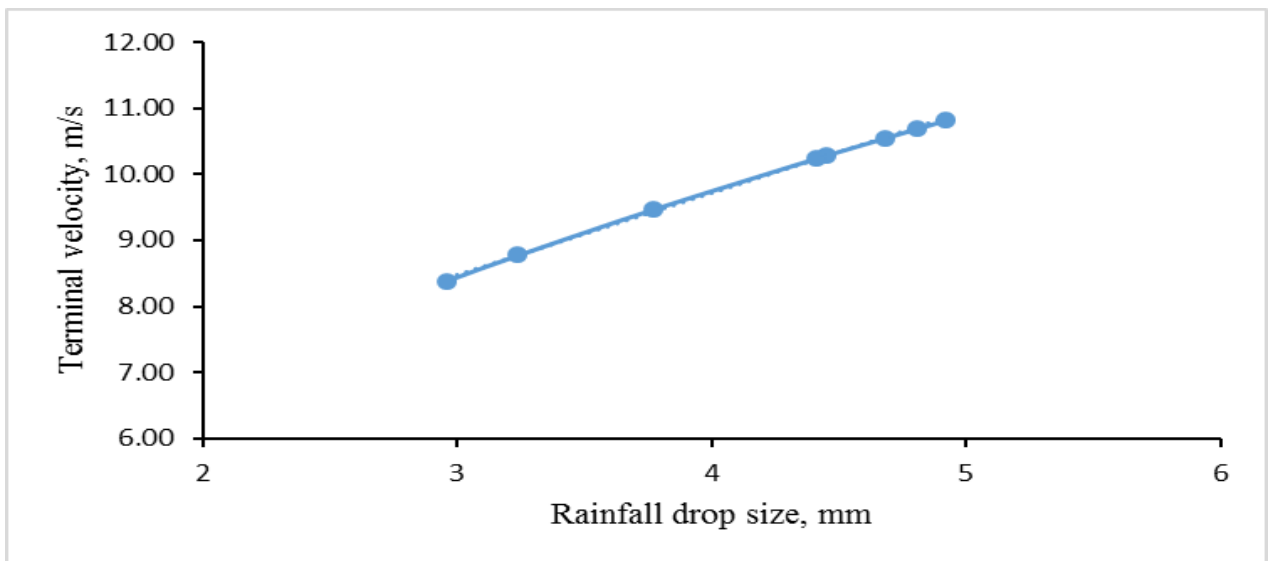

Fig.6 Variation in impact velocity with simulated rainfall drop size

Developed rainfall simulator was found to be capable of producing simulated rainfall with its parameters like intensity, uniformity, drop size, terminal velocity and impact angle similar to natural rainfall. The simulator has the flexibility to function under varying operating pressure to produce rainfall at varying intensities as per requirements of a place. The whole simulation system is mounted on wheels to facilitate movement within the field. Further, dissembling and 
assembling of various simulation units are quite easy which help the simulation system to move to other locations. Thus, the developed rainfall simulation system which is portable, easy to operate and user friendly offers a viable and potent alternative to conduct various hydrological studies under actual field conditions to enhance quality of such research.

\section{Acknowledgement}

The financial assistance received from the College of Technology and physical facilities provided by the Department of Soil and Water Conservation Engineering are hereby duly acknowledged.

\section{References}

Battany, M.C. and Grismer, M.E., 2000. Development of a portable field rainfall simulator for use in hillside vineyard runoff and erosion studies. Hydrological Processes, 14(6), pp.1119-1129.

Bentley, W. A., 1904. Studies of raindrops and raindrop phenomena. Mon Weather Rev, 32, pp.450-456.

Bharali, M. A., 2004. Development and performance evaluation of rainfall simulation systems using hypodermic needles and nozzles. M.Tech thesis Department of Soil and Water Conservation Engineering, G.B.P.U.A\&T, Pantnagar (U. K)

Cerdà, A., Ibanez, S. and Calvo, A., 1997. Design and operation of a small and portable rainfall simulator for rugged terrain. Soil Technology, 11(2), pp.163170.

Corona, R., Wilson, T., D'Adderio, L.P., Porcù, F., Montaldo, N. and Albertson,
J., 2013. On the estimation of surface runoff through a new plot scale rainfall simulator in Sardinia, Italy. Procedia Environmental Sciences, 19, pp.875884.

Dunkerley, D., 2008. Rain event properties in nature and in rainfall simulation experiments: a comparative review with recommendations for increasingly systematic study and reporting. Hydrological Processes: An International Journal, 22(22), pp.44154435.

Fernández-Gálvez, J., Barahona, E. and Mingorance, M.D., 2008. Measurement of infiltration in small field plots by a portable rainfall simulator: application to trace-element mobility. Water, air, and soil pollution, 191(1-4), pp.257264.

Floyd, J. M. at al., 1974. Raindrop characteristics in south central United States. Transactions of the ASAE, 17(6), pp.1033-1037.

Foster, I.D.L., Fullen, M.A., Brandsma, R.T. and Chapman, A.S., 2000. Drip- screen rainfall simulators for hydro- and pedo geomorphological research: the Coventry experience. Earth Surface Processes and Landforms: The Journal of the British Geomorphological Research Group, 25(7), pp.691-707.

Júnior, S. S. and Siqueira, E.Q., 2011, September. Development and calibration of a rainfall simulator for urban hydrology research. In Proceedings of 12th International Conference on Urban Drainage, Porto Alegre, Brazil (pp. 11-16). 
Kathiravelu, G., Lucke, T. and Nichols, P., 2016. Rain drop measurement techniques: a review. Water, 8(1), p.29.

Kumar, A. at al., 2004. Development of a rainfall simulation system using hypodermic needles. Indian journal of soil conservation, 32(3): 198-208.

Lascelles, B., Favis Mortlock, D.T., Parsons, A.J. and Guerra, A.J., 2000. Spatial and temporal variation in two rainfall simulators: implications for spatially explicit rainfall simulation experiments. Earth Surface Processes and Landforms: The Journal of the British Geomorphological Research Group, 25(7), pp.709-721.

Sachin Kumar Singh and Kashyap P. S. 2016. Sediment outflow from paddy mulch at varying land slopes under simulated rainfall conditions. HortFlora Res. Spectrum, 5(4): 275-283

\section{How to cite this article:}

Sachin Kumar Singh and Akhilesh Kumar. 2020. Development of a Portable Rainfall Simulation System for Hydrologic Studies under Field Conditions. Int.J.Curr.Microbiol.App.Sci. 9(01): 1639-1648. doi: https://doi.org/10.20546/ijcmas.2020.901.181 